\title{
Structural Changes in Insulin at a Soft Electrochemical Interface
}

Hum Bahadur Lamichhane, ${ }^{1}$ Terence G. Henares, ${ }^{1}$ Mark J. Hackett ${ }^{1,2, *}$ and Damien W. M. Arrigan ${ }^{1,{ }^{*}}$

${ }^{1}$ School of Molecular and Life Sciences, ${ }^{2}$ Curtin Health Innovation Research Institute, Curtin University, GPO Box U1987,

Perth, Western Australia 6845, Australia

* Corresponding authors,

emails mark.j.hackett@curtin.edu.au (M.J. Hackett), d.arrigan@curtin.edu.au (D.W.M. Arrigan)

\section{List of contents:}

Scheme S1 Schematic representation of the electrochemical cell used

p. S2

Fig. S1 Cyclic voltammograms in the presence and absence of $\operatorname{TPrA}^{+}$.

p. S2

Fig. S2 Amide I region of normalized ATR-FTIR spectra following adsorption at different potentials

p. S3

Fig. S3 Non-normalised ATR FTIR spectra of insulin following electroadsorption at different potentials

p. S4

Fig. S4 ATR FTIR spectra of insulin following electroadsorption at different potentials

p. S4

Fig. S5 Relative proportions of insulin secondary structures at different potentials

p. S5

Fig. S6 Comparison of relative proportions of insulin secondary structures at different potentials.

p. S6

Fig. S7 ATR FTIR spectra of hydrated film of aqueous insulin, solid state insulin, electroadsorbed insulin, organic phase electrolyte salt (BTPPATPBCl) and starting material for preparation of organic phase electrolyte salt (KTPBCl)

p. S7

Figs. S8 \& S9 ATR FTIR spectra of insulin at different concentrations

p. S8 


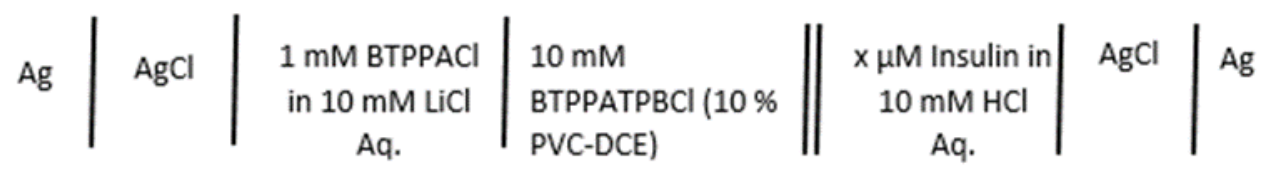

Scheme S1. Schematic of the electrochemical cell composition used. $x=$ concentration of insulin in aqueous phase.

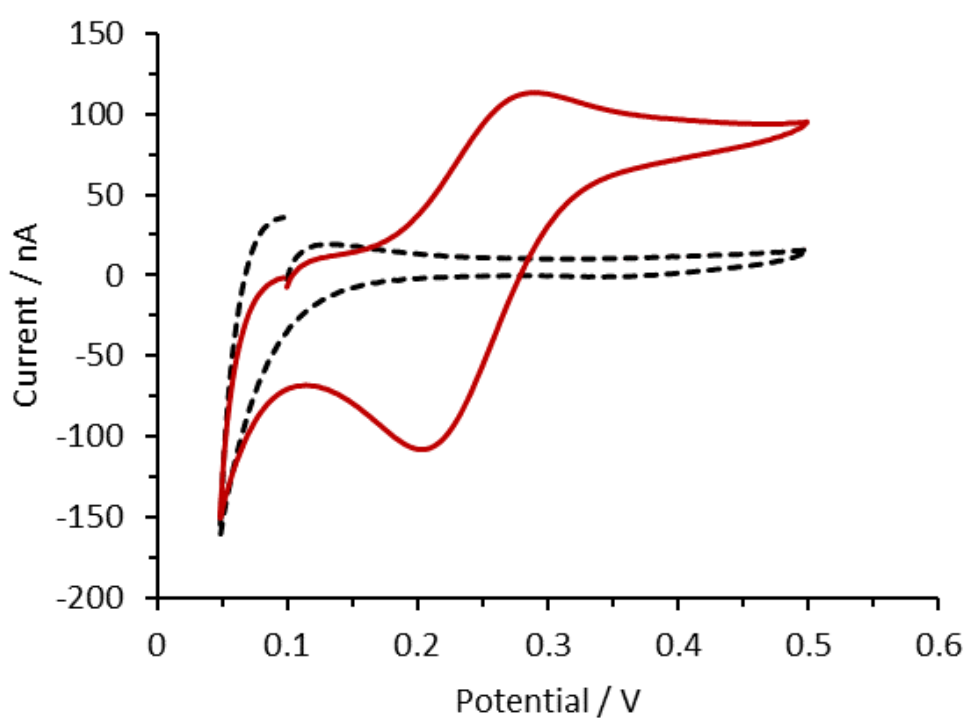

Figure S1. The CV in presence and absence of $\operatorname{TPrA}^{+}$. Scan rate is $10 \mathrm{mVs}^{-1}$ and concentration of $\operatorname{TPrA}^{+}$is $120 \mu \mathrm{M}$. The blank experiment is shown as the dashed line while the TPrA+ transfer is shown as the solid line. 

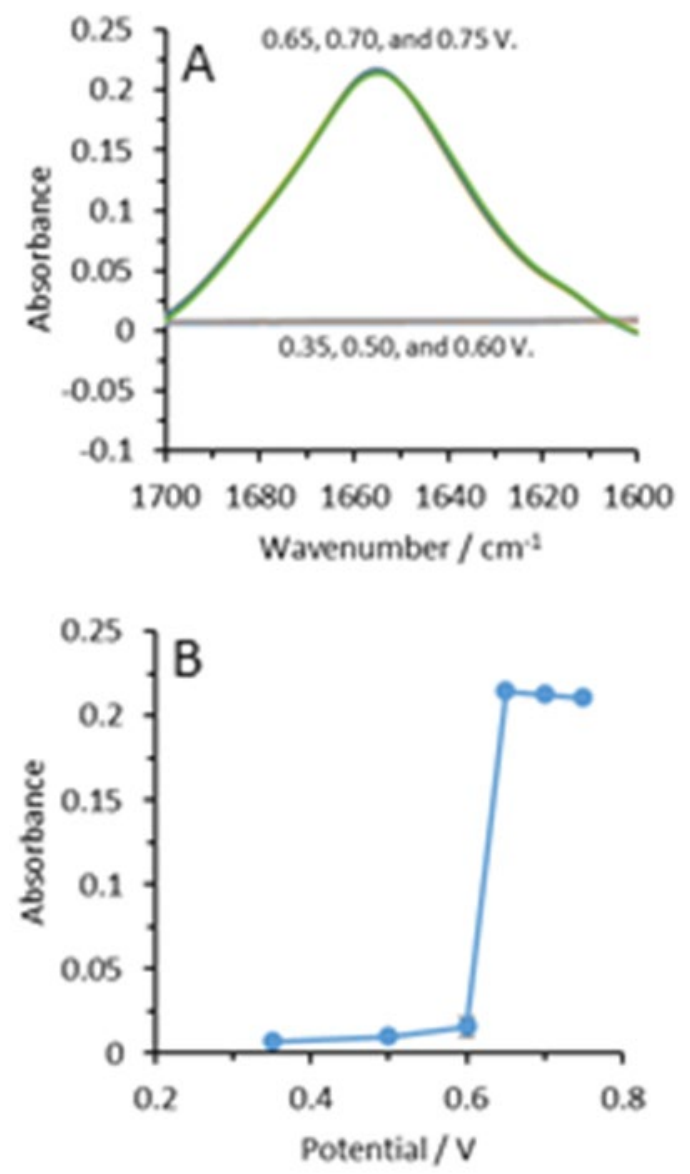

Figure S2. (A) Comparison of the amide I region of normalized spectra following adsorption at $0.35 \mathrm{~V}, 0.50 \mathrm{~V}, 0.60 \mathrm{~V}, 0.65 \mathrm{~V}, 0.70 \mathrm{~V}$, and $0.75 \mathrm{~V}$. (B) Amide I band absorbance of insulin as a function of adsorption potential. Scheme $\mathrm{S} 1, \mathrm{x}=20 \mu \mathrm{M}$; adsorption time $=30 \mathrm{~min}$. Error bars in (B) are \pm 1 standard deviation of three experiments; if not visible, they are smaller than the symbol size. Fig. S3 shows the equivalent nonnormalized data. 

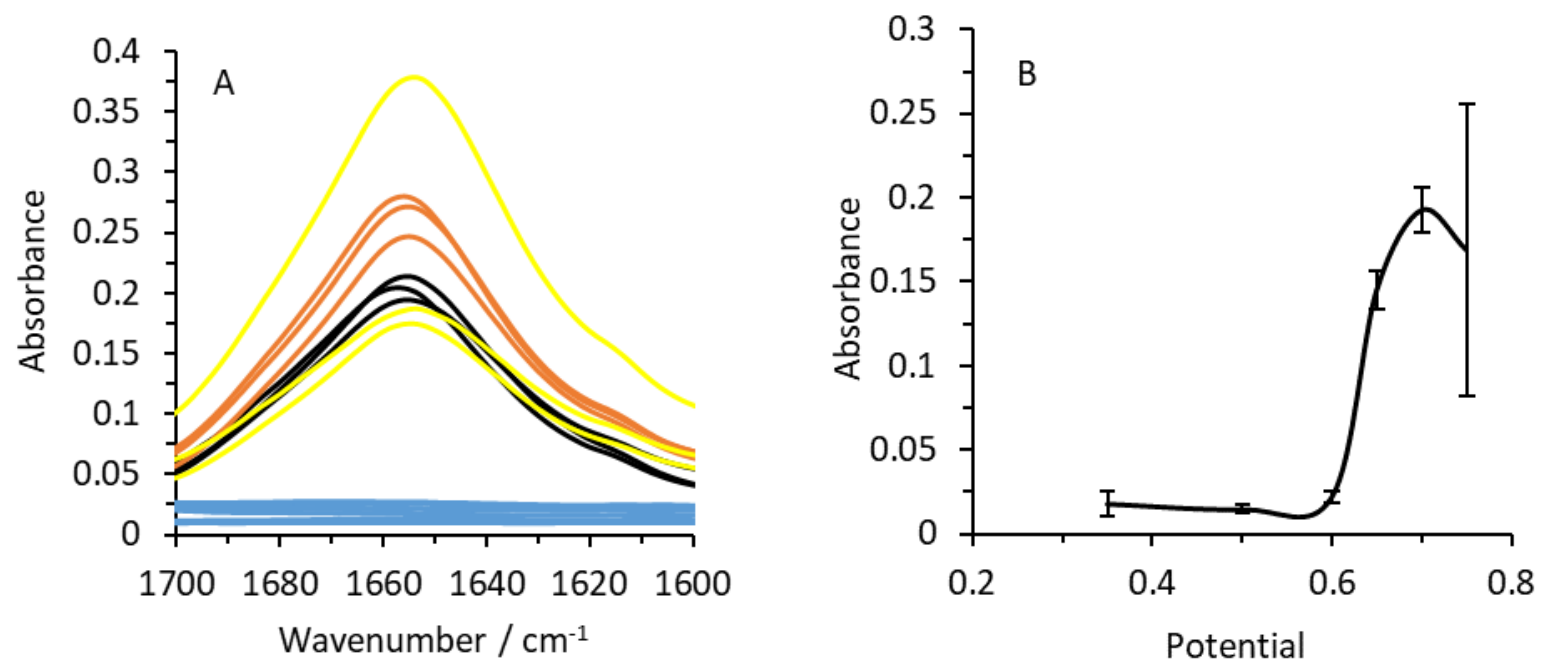

Figure S3. (A) Non-normalised FTIR spectra of insulin showing amide I bands at adsorption potentials $0.65 \mathrm{~V}$ (Black), $0.70 \mathrm{~V}$ (Orange), and $0.75 \mathrm{~V}$ (Yellow). Blue lines shows the amide I bands of insulin (non-normalised FTIR spectra) at adsorption potentials $0.35 \mathrm{~V}, 0.50 \mathrm{~V}$, and $0.60 \mathrm{~V}$. (B) Plot indicating the variation of absorbance with applied adsorption potentials. Aqueous phase: $20 \mu \mathrm{M}$ in $10 \mathrm{mM} \mathrm{HCl}$; Organic phase: $10 \mathrm{mM}$ BTPPATPBCl-1,2-DCE (10\% w/v PVC). 30 min adsorption time. Error bars represent \pm 1 standard deviation obtained from three trials.

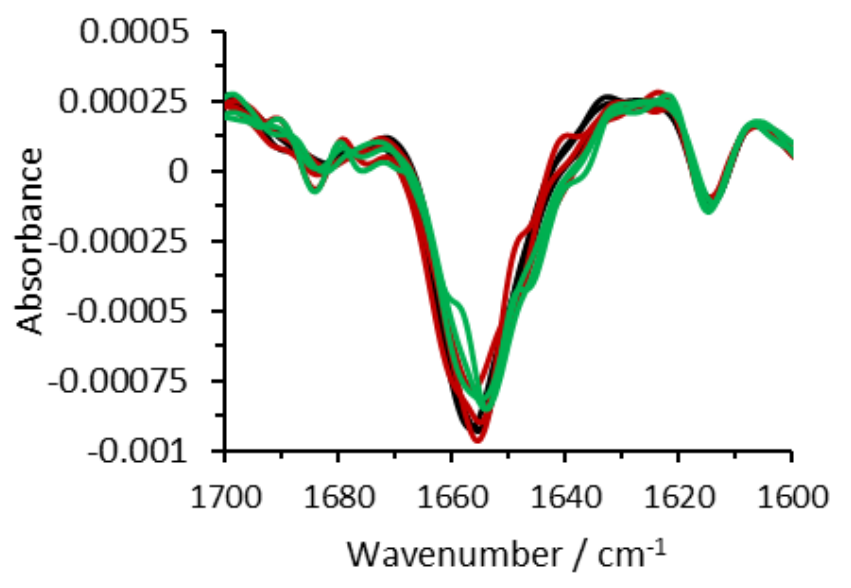

Figure S4. Comparison of the second derivative of amide I regions of electroadsorbed insulin using $20 \mu \mathrm{M}$ aqueous insulin at $30 \mathrm{~min}$ adsorption at different potential i.e. 0.65V (Red line), 0.70V (Black line) and 0.75V (Green line). 10 $\mathrm{mM} \mathrm{HCl}$ as the aqueous phase and $10 \mathrm{mM}$ BTPPATPBCl-1,2-DCE (10\% w/v PVC) as the organic phase. 

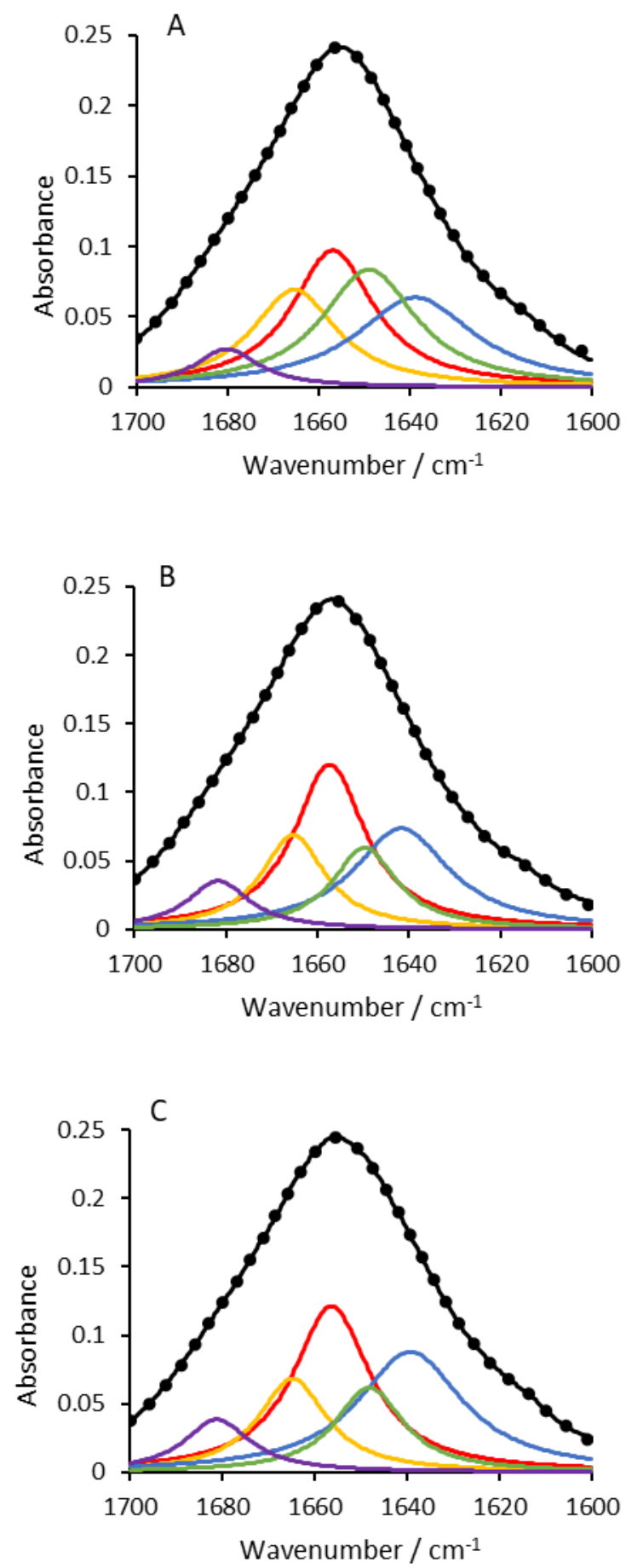

Figure S5. Figure showing the different relative proportion of $\alpha$-helix (Red line), combined $\beta$-sheet and irregular helix (Blue line), $3_{10}$ helix (Yellow line), unordered structures (Green line), and turn (Violet line) of insulin at three different potentials (A) $0.65 \mathrm{~V}$, (B) $0.70 \mathrm{~V}$ and (C) $0.75 \mathrm{~V}$. Adsorption time: $30 \mathrm{~min}$. Aqueous phase: $20 \mu \mathrm{M}$ insulin in $10 \mathrm{mM} \mathrm{HCl}$; organic phase: $10 \mathrm{mM}$ BTPPATPBCl-1,2-DCE (10\% w/v PVC). 


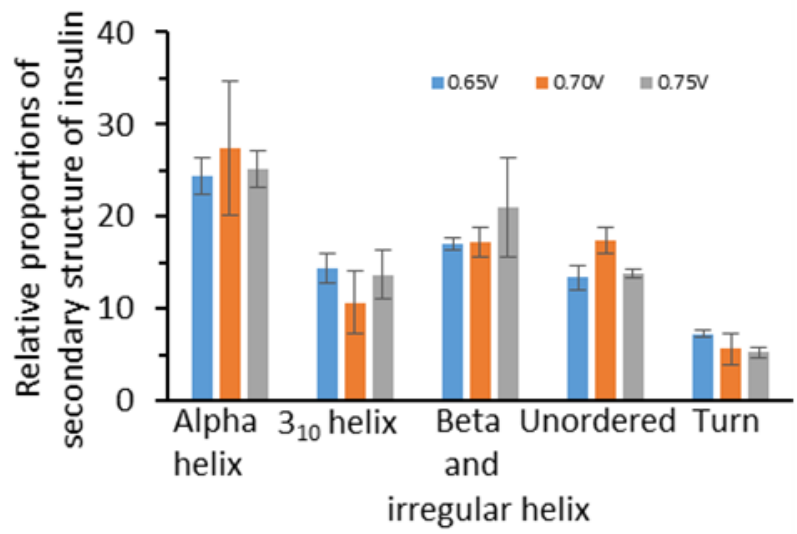

Figure S6. Comparison of relative proportions of different secondary structures of electroadsorbed insulin at different potentials i.e. $0.65 \mathrm{~V}$, $0.70 \mathrm{~V}$, and $0.75 \mathrm{~V}$. Aqueous phase: $20 \mu \mathrm{M}$ insulin in $10 \mathrm{mM} \mathrm{HCl}$; organic phase: $10 \mathrm{mM}$ BTPPATPBCl-1,2-DCE (10 \% w/v PVC). Adsorption time: $30 \mathrm{~min}$. Error bars are \pm 1 standard deviation from three trials 

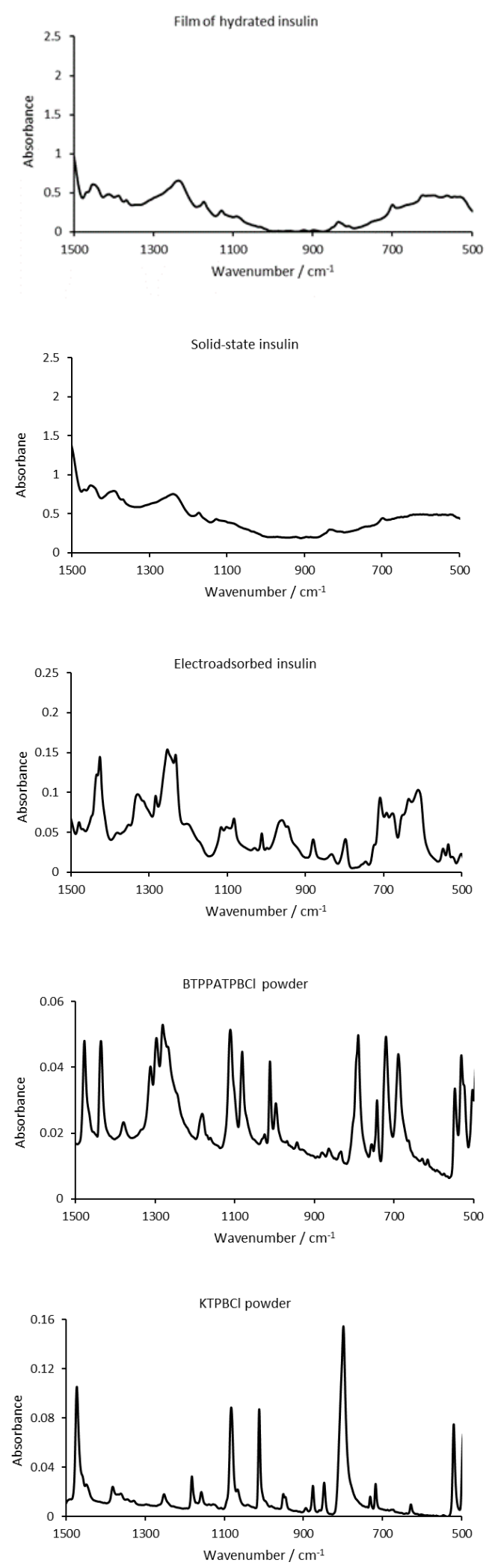

Figure S7. ATR-FTIR spectra of (from top to bottom) film of hydrated insulin, solid state insulin, electroadsorbed insulin, BTPPATPBCl (organic phase electrolyte salt) and KTPBCl (starting material for preparation of organic phase electrolyte salt). Common peaks at ca. 800,1000 , and 1100 $\mathrm{cm}^{-1}$ in electroadsorbed insulin, BTPPATPBCl and KTPBCl suggest the presence of insulin-TPBCl complexes in electroadsobed insulin. 


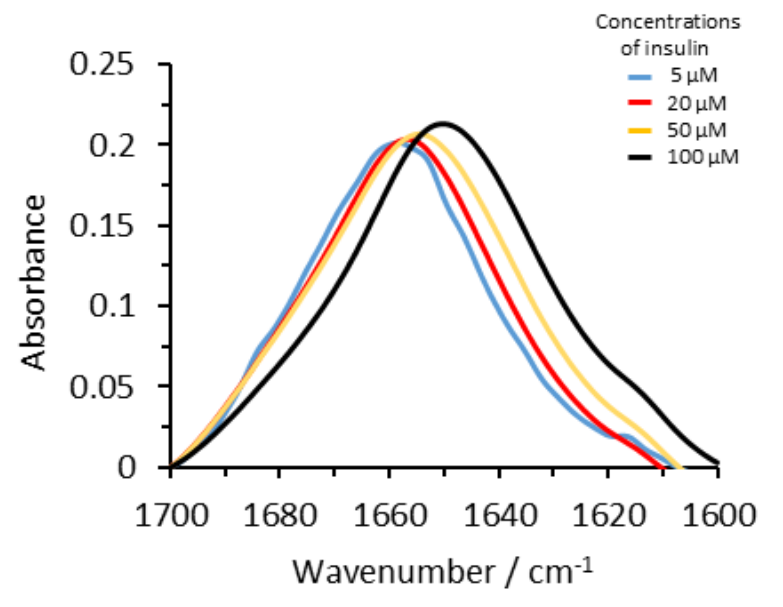

Figure S8. Amide I regions of electroadsorbed insulin at different concentrations. Aqueous phase: $10 \mathrm{mM}$ $\mathrm{HCl}+$ indicated insulin concentration; organic phase: $10 \mathrm{mM}$ BTPPATPBCl-1,2-DCE (10 \% w/v PVC).

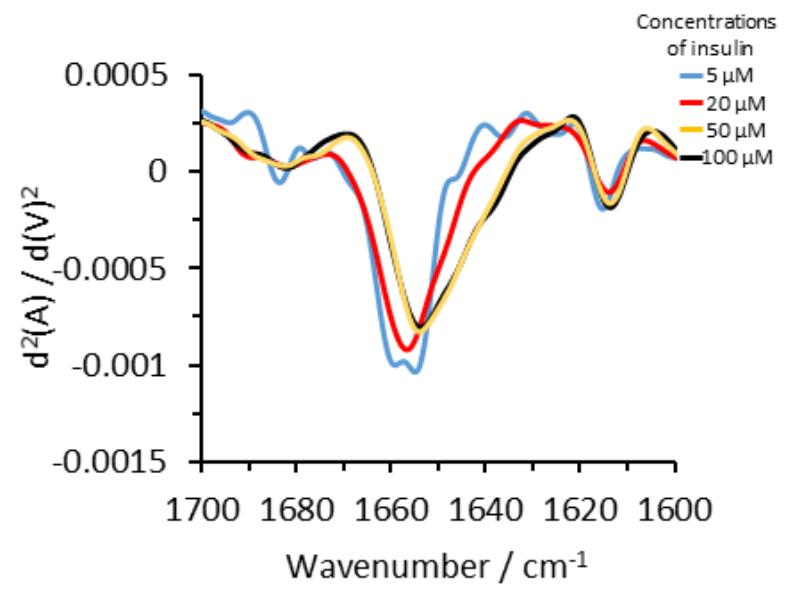

Figure S9. Second derivatives of amide I regions of electroadsorbed insulin at different concentrations. Aqueous phase: $10 \mathrm{mM} \mathrm{HCl}+$ indicated insulin concentration; organic phase: 10 mM BTPPATPBCl-1,2-DCE (10\% w/v PVC). 